\title{
Focused ultrasound in neurosurgery: a historical perspective
}

\author{
*Maya Harary, BA, David J. Segar, MD, Kevin T. Huang, MD, lan J. Tafel, MD, \\ Pablo A. Valdes, MD, PhD, and G. Rees Cosgrove, MD, FRCSC \\ Harvard Medical School and Department of Neurosurgery, Brigham and Women's Hospital, Boston, Massachusetts
}

\begin{abstract}
Focused ultrasound (FUS) has been under investigation for neurosurgical applications since the 1940s. Early experiments demonstrated ultrasound as an effective tool for the creation of intracranial lesions; however, they were limited by the need for craniotomy to avoid trajectory damage and wave distortion by the skull, and they also lacked effective techniques for monitoring. Since then, the development and hemispheric distribution of phased arrays has resolved the issue of the skull and allowed for a completely transcranial procedure. Similarly, advances in MR technology have allowed for the real-time guidance of FUS procedures using MR thermometry. MR-guided FUS (MRgFUS) has primarily been investigated for its thermal lesioning capabilities and was recently approved for use in essential tremor. In this capacity, the use of MRgFUS is being investigated for other ablative indications in functional neurosurgery and neurooncology. Other applications of MRgFUS that are under active investigation include opening of the blood-brain barrier to facilitate delivery of therapeutic agents, neuromodulation, and thrombolysis. These recent advances suggest a promising future for MRgFUS as a viable and noninvasive neurosurgical tool, with strong potential for yet-unrealized applications.

https://thejns.org/doi/abs/10.3171/2017.11.FOCUS17586
\end{abstract}

KEY WORDS focused ultrasound; therapeutic ultrasound; image-guided neurosurgery

A LTHOUGH acoustics as a field of study dates as far back as ancient Greece, it only became an applied science in the 19th century. ${ }^{33}$ In 1880 , brothers Pierre and Jacques Curie described the ability of sound waves in the form of pressure waves to generate an electrical charge when applied to quartz crystals. ${ }^{12}$ They named this phenomenon "piezoelectricity," from the Greek "piezo" for pressure. They also demonstrated the reverse phenomenon: the conversion of electrical charge into sound waves. ${ }^{12}$ With the extension of their discoveries to frequencies above the audible human range $(>20 \mathrm{kHz})$, the field of ultrasonics was born.

In World War I, ultrasound (US) was first put into practical use as sonar in submarines. ${ }^{3}$ In the post-World War I period and to this day, the study and application of US in the field of medicine has been divided into 2 tracks: diagnostic and therapeutic. Several innovations, beginning with a fundamental understanding of US and culminating in phase correction and real-time MRI thermometry, have elevated US to a powerful therapeutic tool with the potential for diverse applications.

\section{Physics of Focused Ultrasound}

Sound waves are mechanical vibrations that occur through a medium in which molecules oscillate in the direction of wave propagation with frequencies higher than $20 \mathrm{~Hz}$. US waves are typically generated using a piezoelectric (PE) transducer operating at $200 \mathrm{kHz}$ to $4 \mathrm{MHz}$, depending on the clinical application. ${ }^{46,62} \mathrm{PE}$ elements have the unique property of expanding and contracting as a function of the applied voltage, and as they expand and relax, they create US waves in the medium.

PE transducers can be single or multiple, curved or flat in configuration, static or moved mechanically. Transducers can include focusing components, such as radiators, lenses, or reflectors, to enable focal delivery of US waves for tissue ablation. ${ }^{34,35,62}$ In 1935, Gruetzmacher first designed a curved quartz plate which, as opposed to previous linear plates, could concentrate US beams at a focus, thus creating the first focused US (FUS) transducer. ${ }^{20}$ Current systems use phased array transducers with hundreds to thousands of PE elements, which can be used to create

ABBREVIATIONS BBB = blood-brain barrier; ET = essential tremor; FUS = focused US; HIFU = high-intensity FUS; MRgFUS = MR-guided FUS; PD = Parkinson's disease; PE = piezoelectric; US = ultrasound

SUBMITTED October 1, 2017. ACCEPTED November 14, 2017.

INCLUDE WHEN CITING DOI: 10.3171/2017.11.FOCUS17586.

* Ms. Harary and Dr. Segar contributed equally to this work and share first authorship. 
multiple focal points to increase the volume of ablation and/or correct for aberrations due to tissue heterogeneities (e.g., bone). ${ }^{29,32,34,35,62}$

Tissue acoustic impedance is a function of substance density and US speed within that substance. As US waves propagate through tissue, they undergo absorption, refraction, and/or reflection, depending on the tissue's impedance properties. These processes, particularly absorption and reflective scatter, result in the exponential attenuation of the US waves. The absorption of acoustic energy translates into temperature elevations in tissue, and, although FUS can disrupt tissue by mechanical forces as well, thermal ablation is the best understood and most significant contributor to the effect of FUS in current applications in neurosurgery. ${ }^{34,35,62}$ The degree of temperature elevation depends on both tissue characteristics, such as intrinsic ultrasonic and heat transfer properties, and the parameters of sonication, including exposure time and intensity of acoustic energy. In FUS applications, the intensity at the focus of the beam is much higher, enabling significant deposition of ultrasonic energy, leading to focused thermal heating. ${ }^{33,35,46,66}$ When tissue is heated to $57^{\circ} \mathrm{C}-60^{\circ} \mathrm{C}$ or greater, beyond the threshold for protein denaturation, coagulation necrosis occurs. ${ }^{6,35,46}$ Mechanical forces are not as well understood, but it is believed that US waves cause formation of microbubbles that then oscillate in the presence of continued US waves (i.e., expanding and contracting). ${ }^{33}$ This process, known as cavitation, leads to creation of shock waves with high pressures and shear forces causing direct mechanical damage to tissue. ${ }^{62}$

\section{From the Laboratory to the Clinic: Development of FUS for Therapeutic Applications}

The first report of in vivo testing of FUS in the brain was by Lynn et al. in their 1943 animal experiments conducted at Columbia University. ${ }^{42}$ They used a curved FUS transducer (Fig. 1) to sonicate a focus at a $5.5-\mathrm{cm}$ depth from the surface of the scalp. The sonication (835 $\mathrm{kHz}$ for 5-15 minutes) caused significant damage to the overlying scalp, skull, and meninges. In their earlier experiments with ex vivo beef liver, they observed that high-intensity FUS (HIFU) with instantaneous ramp-up to maximum intensity was shown to maximize effects at the focus and minimize effects near the source (Fig. 2) ${ }^{43}$ However, this rapid ramp-up resulted in damage to the quartz crystal, and early experiments were limited by a slower increase in signal intensity. Despite the technical limitations at the time, these findings established HIFU as an appropriate methodology for the creation of distinct foci while minimizing trajectory side effects. They also noted that surface and trajectory damage were inversely correlated with focal distance, and inferred that the technology might be more suitable for deep brain targets as opposed to cortical targets. As absorption is proportional to frequency, the authors advised that using a frequency lower than $835 \mathrm{kHz}$ is likely to minimize absorption and heating by superficial tissue and maximize absorption at the focus. ${ }^{42,43}$

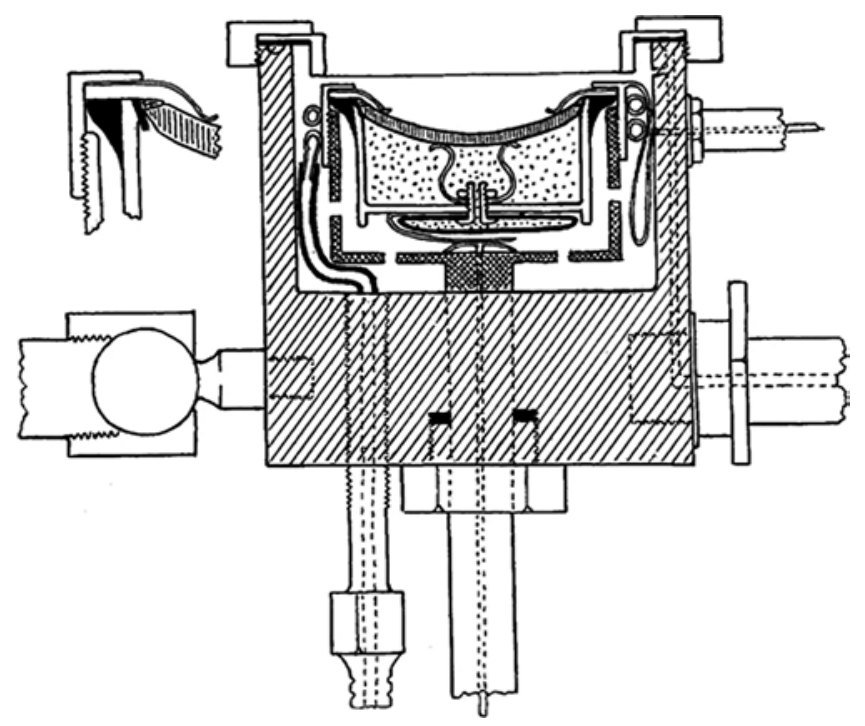

FIG. 1. Lynn's FUS transducer. Reproduced from Lynn JG, Zwemer $\mathrm{RL}$, Chick AJ, Miller AE: A new method for the generation and use of focused ultrasound in experimental biology. J Gen Physiol 26:179-193, 1942, with permission from Rockefeller University Press.

Lynn et al. made several other important observations in animals. At a 5.5-cm depth, the focus was in cortical and peripheral subcortical regions. The treated animals displayed neurological dysfunction lasting 2-16 hours, which correlated with the location of sonication..$^{42}$ For example, targeting of motor cortex, visual cortex, and cerebellum resulted in transient monoparesis, blindness, and ataxia, respectively. These results implied that FUS could create reversible neuronal lesions. In addition, it was observed that ganglion cells were more sensitive to FUS relative to glia and blood vessels. The minimal damage to blood vessels, when it did occur, was associated with edema and occasional petechial hemorrhage, typically near the tissue interface.

Several years later, William and Francis Fry made the next leap in the field of FUS at the University of Illinois. Given the surface damage seen in the Lynn experiment and concerns about disruption of signal focus, the Fry brothers decided to deliver FUS directly to the dural surface via a craniotomy. Learning from their predecessors, they turned their attention away from cortical and subcortical targets to deep brain targets. In a 1954 paper, Fry's group described their method for targeting deep brain structures using a 4-beam irradiator (Fig. 3) that could be moved in relation to a stereotactic apparatus, a concept that was already established for use in lesioning procedures for deep brain targets. ${ }^{19}$ This work was the first to demonstrate effective use of stereotaxy in conjunction with FUS in an animal model. Effective lesioning of the thalamus and internal capsule in 31 cats was confirmed on histology, with cellular changes to the irradiated targets shown as soon as 2 hours postprocedure (Fig. 4). In contrast to Lynn's prior work, there was a strong predilection for ultrasonic destruction of nerve fibers over cell bodies; while targeted thalamic cell bodies were histologically unaffected by the lesions in this experiment, axons in the internal capsule 
TABLE III

Beef Liver Changes Produced by Focused Ulirasound

\begin{tabular}{|c|c|c|c|c|c|}
\hline Liver block experiment..... & 1 & 2 & 3 & 4 & 5 \\
\hline T-200 plate, volts...... & 600 & 1750 & 1750 & 2410 & $2410 \rightleftarrows+$ \\
\hline T-200 plate, $a m p . . . . .$. & 0.060 & 0.120 & 0.120 & 0.220 & $0.220 \rightleftarrows+$ \\
\hline R.F. output, $a m p . . \ldots$ & 0.200 & 0.700 & 0.700 & 0.900 & $\begin{array}{c}0.900 \rightleftarrows 1.00 \\
+ \\
\end{array}$ \\
\hline Total exposure time, sec. & 30 & 30 & 180 & 30 & 20 \\
\hline $\begin{array}{l}\text { Time from } 0 \text { to power } \\
\text { indicated, sec....... }\end{array}$ & 10 & 10 & 10 & 10 & Instantaneous \\
\hline $\begin{array}{c}\text { Diagram of longitudinal } \\
\text { section of liver } \\
\text { changes } \ldots \ldots \ldots \ldots \ldots\end{array}$ & & & & & 8 \\
\hline
\end{tabular}

FIG. 2. The effect of sonication characteristics on shape of lesion. Lynn's experiment on beef liver. Reproduced from Lynn JG, Zwemer RL, Chick AJ, Miller AE: A new method for the generation and use of focused ultrasound in experimental biology. $J$ Gen Physiol 26:179-193, 1942, with permission from Rockefeller University Press.

were irreversibly damaged in the focal target. ${ }^{19}$ Blood vessels and surrounding tissue showed no evidence of damage at the dosages and times used to create the lesion.

Also in 1954, Petter Aron Lindstrom investigated the use of FUS to perform prefrontal lobotomies in an animal model. ${ }^{39}$ He later collaborated with Lars Leksell, using Leksell's custom stereotactic frame, to create deep brain lesions. Seeing the challenges posed by the skull, Leksell turned his attention to the use of ionizing radiation as opposed to US, and in later years, his work laid the foundations for the field of radiosurgery.

Meanwhile, the Fry laboratory went on to demonstrate the neurophysiological properties of lesional reversibility that had been described clinically by Lynn et al. Cortical activity generated in response to flashes of light to the retina, measured by electrodes overlying the visual cortex, could be reversibly suppressed with the correct ultrasonic stimulation of the lateral geniculate nucleus. At the end of the ultrasonic irradiation, the primary evoked potential amplitudes were reduced to less than one-third of baseline but returned to prior baseline within 30 minutes after stimulation was complete. The doses used for this study had been demonstrated to cause no histological change to the underlying neural tissue and introduced the novel concept of FUS neuromodulation. ${ }^{17}$

Given the success of the multibeam irradiation in creating focused lesions in animals, the Fry laboratory-in conjunction with the neurosurgery department at the University of Iowa-published the first use of multibeam FUS in human neurosurgery, targeting deep brain structures for treatment of tremor and rigidity in Parkinson's disease (PD) ${ }^{51}$ In 1960, Meyers and Fry reported on 48 patients treated with ultrasonic therapy, with significant emphasis on treatment of tremor and rigidity associated with PD (Fig. 5). ${ }^{18}$ Their early studies also included forays into treatment of involuntary movement associated with cerebral palsy and pain syndromes. ${ }^{20}$

By the second half of the 20th century, the ability to create focal lesions using FUS was established. However, since it required a craniotomy to avoid surface tissue damage and distortion of US beams by the skull, it was more

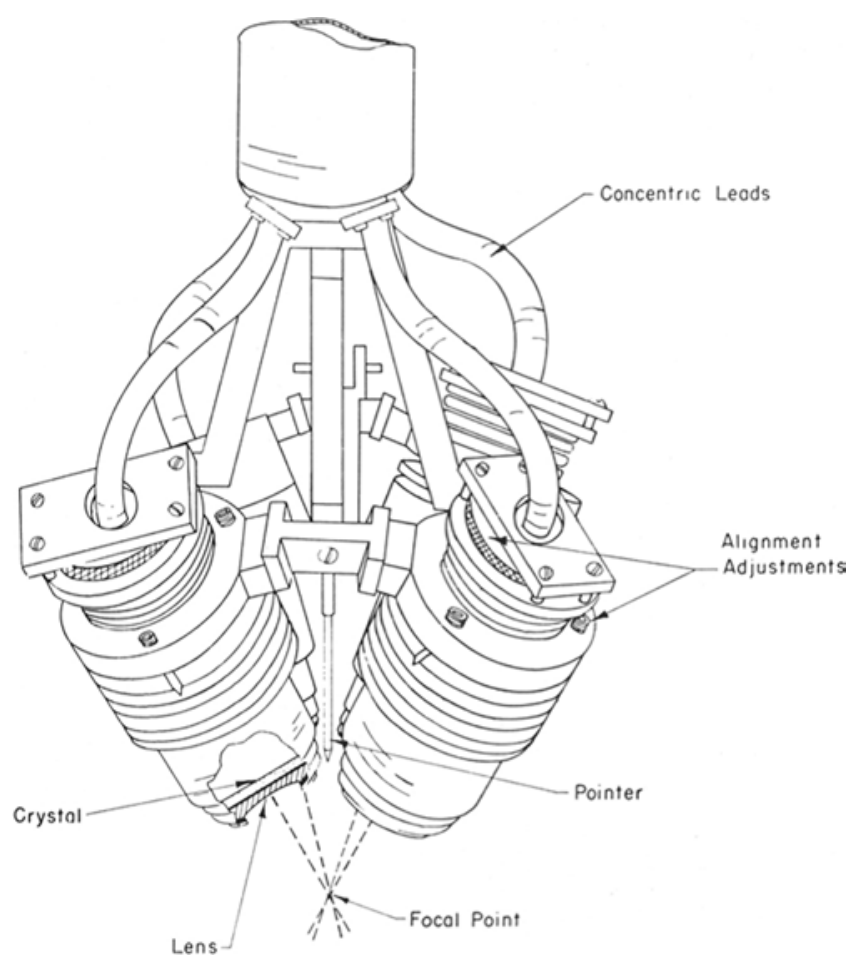

FIG. 3. Fry's 4-beam transducer. Reproduced from Fry WJ, et al: J Neurosurg 11:471-478, 1954, with permission. 


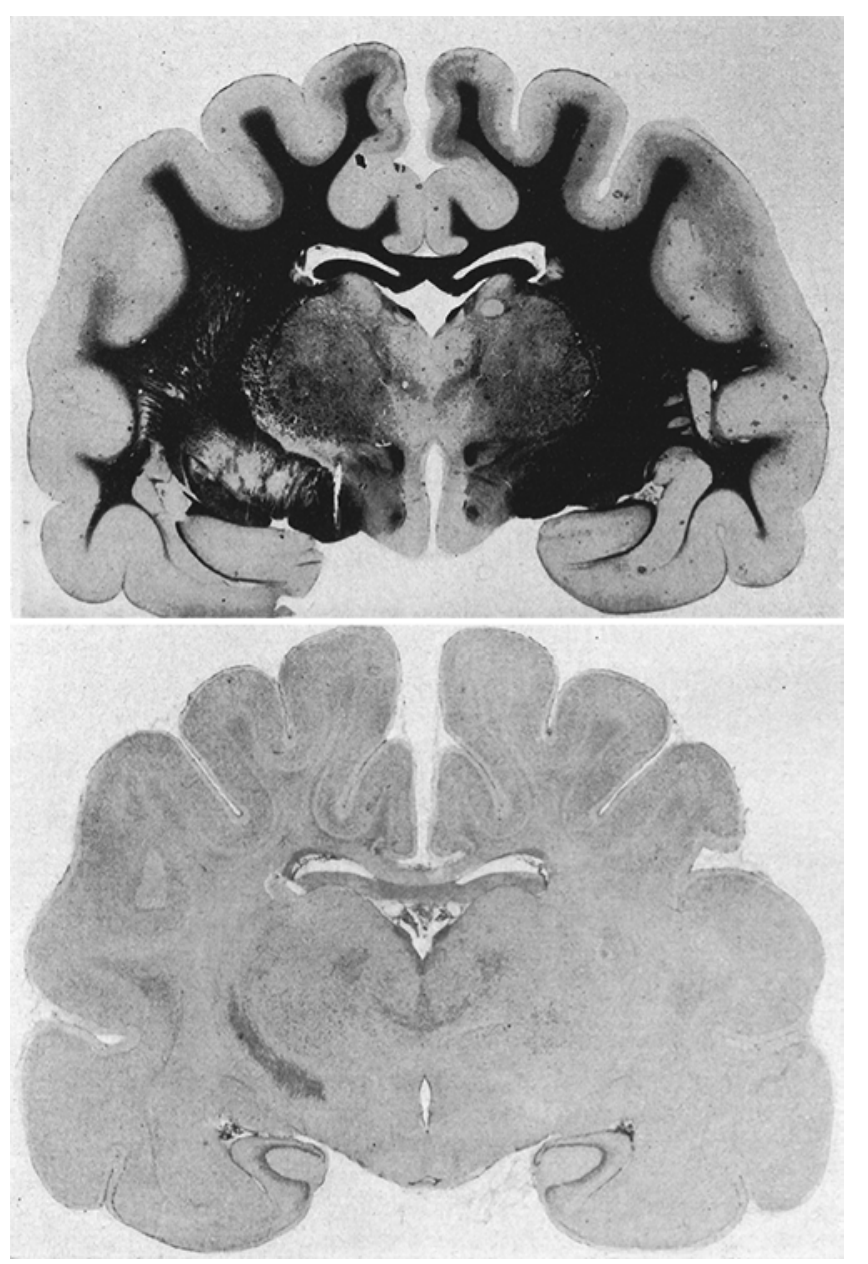

FIG. 4. Fry's capsulotomy in 2 cat brains that had been irradiated at $210 \mathrm{~W} / \mathrm{cm}^{2}$ for 4.0 seconds. Upper: Weil stain, 3 days postoperatively. Lower: Thionin stain, 30 days postoperatively. Reproduced from Fry WJ, et al: J Neurosurg 11:471-478, 1954, with permission.

invasive than the other methods of functional neurosurgery practiced at the time, including stereotactic lesioning and, later, deep brain stimulation (DBS). Two challenges - transcranial application and real-time procedural monitoring-remained for this technology to compete with its contemporaries.

\section{The Issue of the Skull}

To create a completely transcranial method and obviate the need for a craniotomy, advances in FUS had to overcome 2 major obstacles: localized heating at the skull and inaccurate beam propagation due to surface tissue heterogeneities. Acoustic attenuation is approximately 30-60 times higher in bone than in soft tissue. Noted even by Lynn et al. in their early experiments, the interaction of US waves with the skull causes rapid, localized heating at the skull, limiting the levels of energy that can be safely applied..$^{46}$ This problem was ultimately solved by using a hemispheric transducer at lower frequencies with active scalp cooling, in which circulating water prevents heating and improves the transducer-cranial interface. ${ }^{46}$ Lower

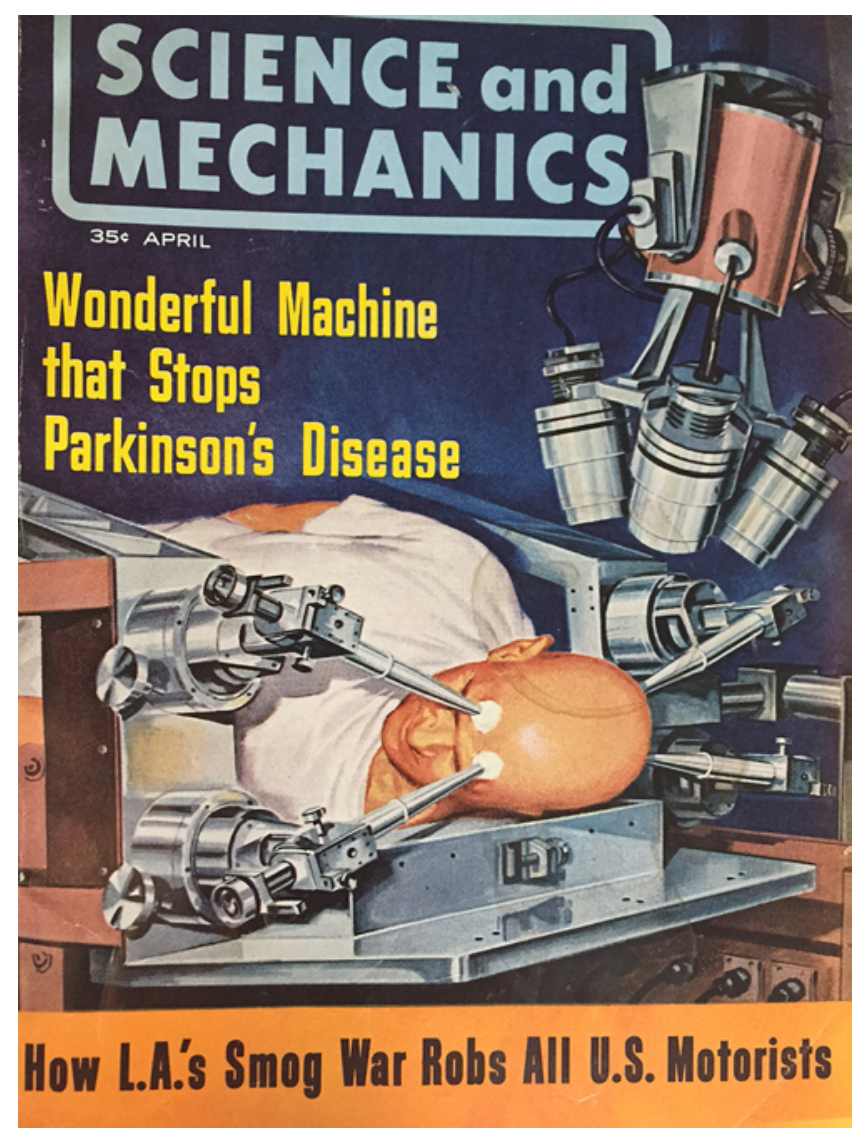

FIG. 5. Science and Mechanics magazine cover featuring Meyers and Fry's work, April 1963. Copyright elapsed, figure in public domain.

frequencies lead to reduced absorption at the surface, and the hemispheric arrangement distributes localized heating over a large surface area. ${ }^{46}$

As an additional confounding factor, beam propagation and focus are significantly distorted by the impedance mismatch between bone and brain, as well as individual variations in skull shape, thickness, and marrow-to-cortical bone ratio. Even into the early 1990s, this problem was insurmountable. The creation of a phased array, in which individual phase offsets correct for the delays and variations in wave propagation encountered throughout the skull, ${ }^{46}$ allowed for precise targeting previously only possible when targeting through a craniotomy window. After the development of monitoring technology allowing for accurate acoustic feedback,,$^{59}$ a hydrophone was used to calculate the phase shifts generated through human skull. ${ }^{29}$ While successful phase shifting had been used previously in one-dimensional arrays, the 1998 paper by Hynynen and Jolesz was the first to combine a multidimensional array with a successful phase correction method. ${ }^{29}$ Building on this work, the authors went on to demonstrate that phase corrections based on information derived from pretreatment CT scans could enable accurate, patient-specific transcranial FUS treatment. ${ }^{8,27}$ These methods were foundational to the development of modern FUS technology, allowing for the treatment of deep brain structures completely noninvasively. 

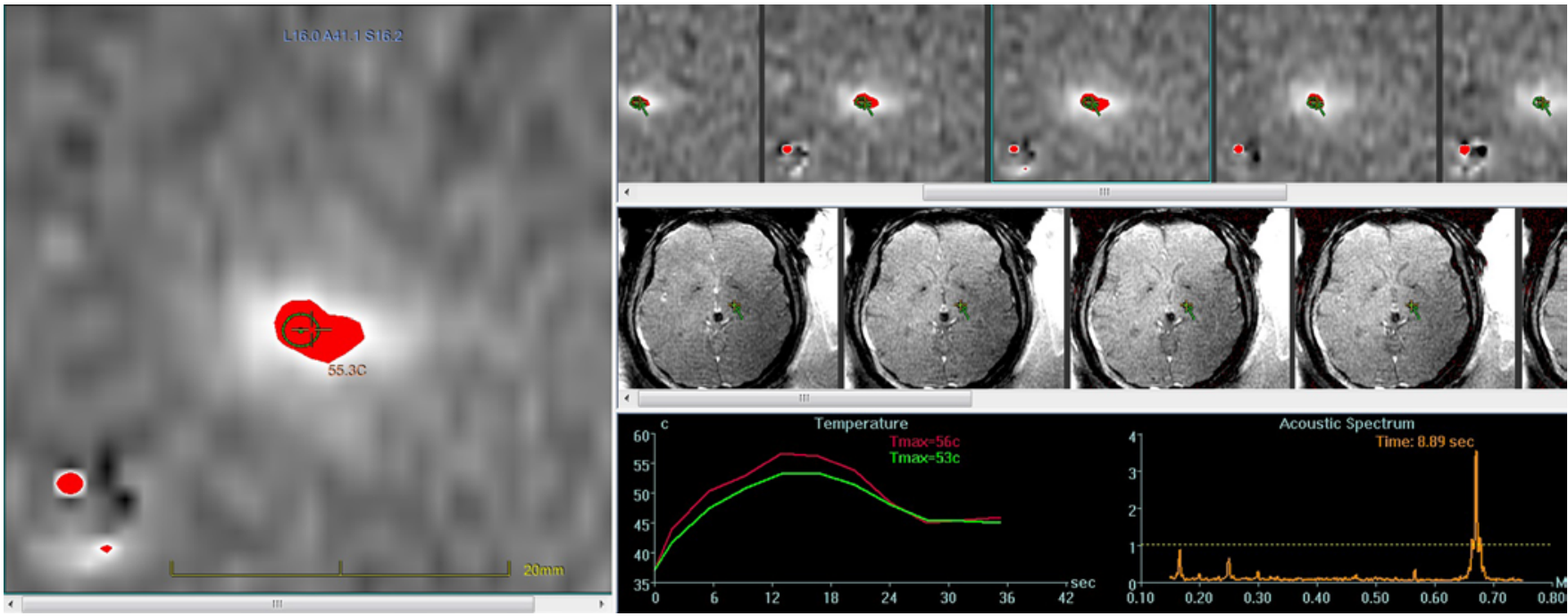

FIG. 6. Real-time monitoring of FUS thalamotomy for ET using MR thermometry. Published with permission from InSightec Inc.

\section{Real-Time Monitoring by MR Thermometry}

The early adopters of HIFU-mediated thermal ablation were general surgeons who employed this technique in prostate, urological, breast, and gynecological tumors. ${ }^{25}$ In these applications, surgeons had a wide soft-tissue window that allowed them to use diagnostic US technology to guide and monitor treatment in real time. In neurosurgical applications, the skull created a major technical obstacle, interfering with ultrasonic visualization of underlying changes to tissue. In the late 1980s to early 1990s, Dr. Ferenc Jolesz's group, working at Brigham and Women's Hospital alongside Drs. Peter Black and Marvin Fried, at the departments of neurosurgery and otorhinolaryngology, respectively, pioneered the development of intraoperative MR image guidance (reviewed by Mislow et al. ${ }^{53}$ ). After the opening of the Advanced Multimodality Image Guided Operating (AMIGO) suite at Brigham and Women's Hospital in the mid-1990s, Jolesz and his contemporaries turned their attention to actualizing intraoperative MR thermometry as a tool to guide FUS procedures by monitoring temperature changes generated at the US focus within the brain in real time..$^{9-11}$

By the late 1990s, Jolesz's group showed that low-power sonications could raise the temperature at the target to $40^{\circ} \mathrm{C}-42^{\circ} \mathrm{C}$ without causing permanent damage. These subthreshold sonications created a heat signature that can be monitored using MR thermometry to help localization and targeting prior to the high-power, ablative sonications. ${ }^{32}$ Real-time monitoring of FUS therapy was needed not only to localize the therapeutic focus but also to supervise the tissue changes associated with thermal damage. As mentioned previously, the temperature needed to cause cellular death via thermal coagulation during a short exposure is approximately $55^{\circ} \mathrm{C}-60^{\circ} \mathrm{C} .{ }^{48,66}$ Not surprisingly, the biological effects caused by temperature elevation generated during the subthreshold sonications do not dissipate instantaneously. Indeed, as early studies on the effects of hyperthermia demonstrated, the extent of tissue damage is related to the overall thermal dose delivered to the target, which is a nonlinear function of the cumulative temperature change and time of sonication. ${ }^{13,49}$ In addition, the energy required by the transducer to generate a goal temperature varies based on patient-specific trajectory characteristics (e.g., skull thickness). In subsequent years, Jolesz and colleagues worked on characterizing thermal dosimetry to a point that eventually allowed for the prediction of lesion size following sequential sonications and for the real-time monitoring of thermal lesioning (Fig. 6). ${ }^{7,47,48}$

In 1996, Jolesz and his group first described the in vivo use of MR-guided FUS (MRgFUS) for the ablation of breast fibroadenomas. ${ }^{28}$ The first neurosurgical application of MRgFUS followed in the early 2000s, as phased arrays became available to effectively target through the intact skull. In 2010, a collaboration between Jolesz's group at Brigham and Women's Hospital and Dr. Kullervo Hynynen at the University of Toronto, reported the first transcranial application of MRgFUS in 3 patients with recurrent, inoperable glioblastomas or brain metastases (Fig. 7). ${ }^{46}$ While the early version of the transducer used in this study was unable to reach suprathreshold temperatures required for ablation, design and engineering modifications to the transducer have since addressed this limitation, and in 2016, the MRgFUS ExAblate 4000 system (InSightec Inc.) was approved by the FDA for intracranial use in the treatment of essential tremor (ET) based on the clinical trial reported by Elias et al. (Fig. 8) ${ }^{15}$

\section{Clinical Applications of MRgFUS}

Given its suitability for the targeting of deep brain structures, MRgFUS has been investigated as a potential treatment modality for the treatment of ET, PD, obsessivecompulsive disorder, major depressive disorder, neuropathic pain, and epilepsy. More recently, research has also focused on 2 possible applications of MRgFUS in neu- 


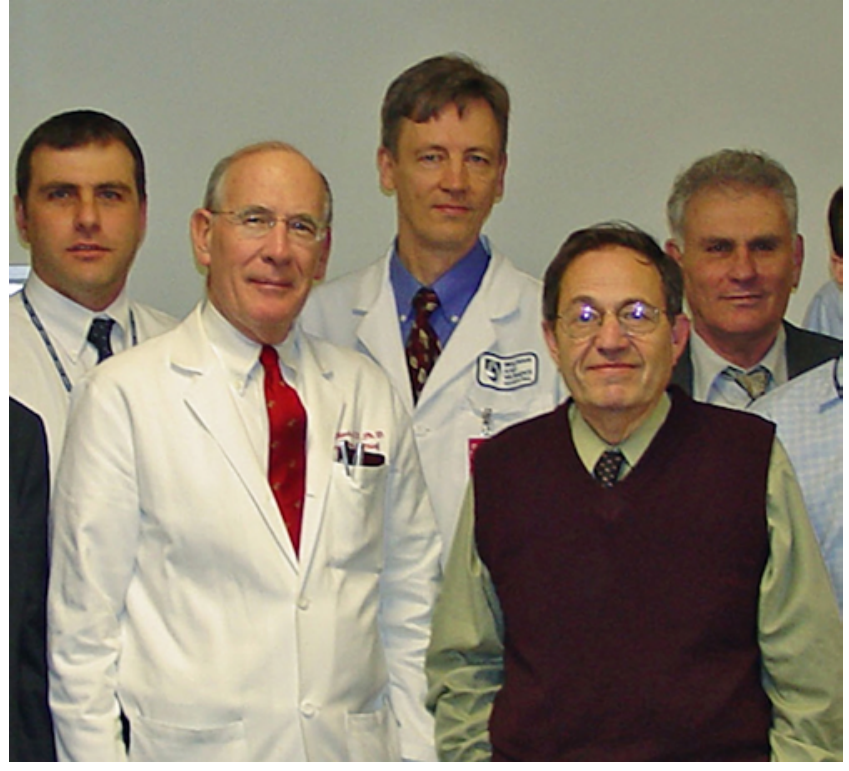

FIG. 7. In 2005, after the first FUS treatment at Brigham and Women's Hospital. Front right, Dr. Ferenc Jolesz; front left, Dr. Peter Black; back center, Dr. Kullervo Hynynen. Reproduced with permission from Dr. Nadir Alikacem.

rooncology: direct tumor ablation and facilitation of drug delivery by selective opening of the blood-brain barrier (BBB).

\section{Essential Tremor}

Unilateral MRgFUS lesioning of the ventral intermediate nucleus of the thalamus was first reported as a treatment for medically refractory ET in 2013.14,40,68 This work was followed in 2016 by a larger, prospective, shamcontrolled trial of the technique..$^{15}$ The experimental group had a mean improvement in tremor score in the treated upper extremity of $47 \%$ at 3 months, sustained at $40 \%$ improvement at the 1-year posttreatment mark. This was accompanied by significant improvement in function and quality of life. The most common adverse events were paresthesia and gait disturbance occurring at rates of 38\% and $36 \%$, and subsequently declining to $14 \%$ and $9 \%$, respectively, at the 1-year mark.

\section{Parkinson's Disease}

MRgFUS thalamotomy has also been reported for the treatment of medically refractory parkinsonian tremor with significant improvement in tremor of both the upper and lower extremities on the treated side at 6 months posttreatment, although there was a trend toward tremor recurrence. ${ }^{58,68}$ The adverse events profile was similar to that reported in earlier MRgFUS thalamotomy work. Jeanmonod et al. subsequently reported their experience targeting the pallidothalamic tract with sonication parameters used for MRgFUS thalamotomy and found a mean improvement of $57 \%$ on the Unified Parkinson's Disease Rating Scale (UPDRS) in a series of 8 patients. ${ }^{34}$ After some modifications to the treatment parameters, patients experienced an improvement of $60.9 \%$ in the UPDRS,

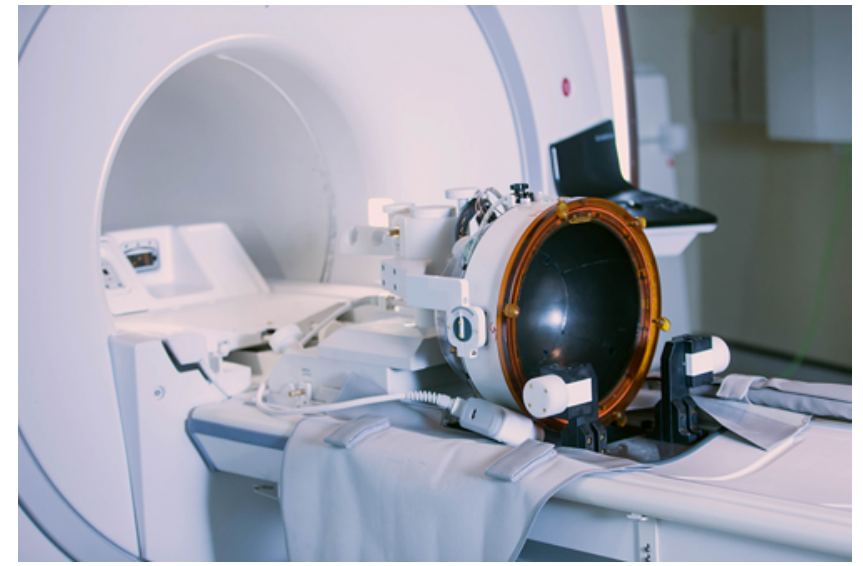

FIG. 8. ExAblate 4000 transducer. Published with permission from InSightec Inc.

comparable to published outcomes from radiofrequency ablation of this area. ${ }^{44}$ Currently MRgFUS is approved for the treatment of parkinsonian tremor and dyskinesia in Europe and Israel, ${ }^{68}$ and is currently undergoing several Phase 1 and 2 clinical trials in North America and Korea looking at a range of targets (clinical trial registration nos. NCT02252380, NCT0200324, and NCT02246374).

\section{Neuropsychiatric Conditions}

Bilateral capsulotomy using MRgFUS resulted in a significant improvement in depression and anxiety, sustained for at least 6 months, in a series of 4 patients with obsessive-compulsive disorder. ${ }^{37}$ This indication is currently undergoing Phase 2 clinical trials in Korea (clinical trial registration no. NCT01986296) and in North America (clinical trial registration no. NCT03156335). Similarly, MRgFUS is also under investigation for the treatment of medication-refractory major depressive disorder (clinical trial registration no. NCT02348411).

\section{Chronic Pain}

MRgFUS lesioning of the central lateral thalamic nucleus for chronic neuropathic pain syndromes in a series of 11 patients showed a $49 \%$ and $57 \%$ pain relief at the 3 -month and 1-year follow-up, respectively. ${ }^{34}$ Trigeminal neuralgia had originally been avoided due to concerns about heating of surrounding sensitive structures. However, in 2013, a cadaveric study demonstrated that with the implementation of "no-pass" regions of the skull base, the trigeminal ganglion could be lesioned without significantly elevating the temperature of surrounding structures. $^{55}$

\section{Epilepsy}

The application of MRgFUS to the treatment of epilepsy has taken 2 approaches: the suppression of epileptic activity and the lesioning of epileptic foci. Animal experiments have demonstrated that low-intensity, pulsed FUS was able to suppress epileptic activity in the cortex of a rat. ${ }^{52} \mathrm{~A}$ feasibility study of low-intensity FUS pulsation for the suppression of temporal lobe epilepsy is currently 
underway (clinical trial registration no. NCT02151175). A feasibility study for MRgFUS lesioning for the treatment of subcortical lesional epilepsy is also underway (clinical trial registration no. NCT02804230).

\section{Direct Tumor Ablation}

Ultrasonographic ablation of malignancies extends as far back as animal studies in Japan in the 1930s and human studies by the Germans and Swiss in the 1940s. ${ }^{22-24,56}$ Given the noninvasive nature of the technology, FUS was theorized to have significant potential for the treatment of surgically inaccessible brain tumors. In 1991, Guthkelch et al. described FUS-mediated tumor ablation via craniotomy in 15 patients with primary high-grade gliomas, but the authors noted inconsistent heating throughout the tumor bed..$^{21}$

In the early 2000s, once MR guidance of FUS procedures was available, investigators revisited MRgFUS as a tool for tumor ablation, using MRgFUS via a craniotomy to ablate glioblastoma lesions in 3 separate patients. ${ }^{57}$ Progression-free survival was 4 and 9 months for 2 of the patients, and the third still had no progression by time of reporting at 39 months after MRgFUS treatment. Notably, 1 of the 3 patients experienced hemiparesis due to the unintended sonication trajectory damage outside the target zone. The first completely transcranial sonication of brain tumors in 3 glioblastoma patients was performed at Brigham and Women's Hospital a few years later. ${ }^{46}$ However, power limitations prevented sufficient heating for tumor ablation and thermal necrosis.

\section{Blood-Brain Barrier}

As far back as the 1950s, Ballantine et al., working at Massachusetts General Hospital, observed the localized extravascular leakage of trypan blue dye, due to US-mediated BBB disruption, in the absence of damage to surrounding neural tissue after FUS sonication., ${ }^{1,2}$ FUSmediated BBB opening occurs via a process of cavitation, as opposed to hyperthermia. Early attempts to harness these effects were complicated by microhemorrhage and damage to neighboring parenchyma. ${ }^{67}$ It was later demonstrated that the intravascular injection of preformed microbubbles at the time of sonication helped concentrate the sonication effect to the intraluminal side of the vessel wall. ${ }^{30,31,60}$ The use of preformed microbubbles meant that a lower-energy sonication could be used to cause BBB opening, reducing effects on surrounding neural tissue and improving the safety profile. ${ }^{31}$

Through the use of specific sonication parameters alongside preformed microbubbles, MRgFUS can open the BBB in a safe, spatially selective, and reversible fashion. ${ }^{31,50,67}$ Preclinical studies have demonstrated the use of FUS to enhance the delivery of a number of chemotherapeutic agents, including biological agents, across the BBB in rats, ${ }^{41,63,64}$ rabbits, ${ }^{38}$ and nonhuman primates. ${ }^{45}$ Additional studies have applied this technology to deliver other substances, including stem cells, nucleic acids, and antibodies, for the treatment of neurodegenerative diseases. ${ }^{4,5}$, ${ }^{36,38}$ Although no human trials have been completed as of yet, MRgFUS-mediated BBB opening remains an active area of exploration. ${ }^{26}$

\section{Intracranial Thrombolysis}

Prior research has demonstrated that application of US enhances intravascular thrombolysis when administered along with tissue plasminogen activator. ${ }^{65}$ FUS for the treatment of ischemic stroke, however, remains in the early preclinical phase, with in vitro and animal models having demonstrated initial feasibility. ${ }^{16,61}$ MRgFUS has also been explored for thrombolysis in intraparenchymal hemorrhage. Results from a cadaveric animal model of intracranial hemorrhage demonstrated that FUS led to sufficient clot liquefaction to allow for needle aspiration of the lysate..$^{54}$

\section{Conclusions}

After decades of research across multiple institutions, many of the early technological obstacles to the clinical use of FUS have been resolved, and MRgFUS is now a powerful neurosurgical tool. Applications involving direct lesioning of neural tissue are by far the closest to routine clinical use. Other applications of MRgFUS technology remain in early clinical and preclinical development stages. Nonetheless, considering the promising and potentially exciting indications under investigation, we appear to be poised on the threshold of a golden age for this technology.

\section{References}

1. Bakay L, Ballantine HT Jr, Hueter TF, Sosa D: Ultrasonically produced changes in the blood-brain barrier. AMA Arch Neurol Psychiatry 76:457-467, 1956

2. Ballantine HT Jr, Hueter TF, Nauta WJ, Sosa DM: Focal destruction of nervous tissue by focused ultrasound: biophysical factors influencing its application. J Exp Med 104:337-360, 1956

3. Briquard P: Paul Langevin. Ultrasonics 10:213-214, 1972

4. Burgess A, Ayala-Grosso CA, Ganguly M, Jordão JF, Aubert I, Hynynen K: Targeted delivery of neural stem cells to the brain using MRI-guided focused ultrasound to disrupt the blood-brain barrier. PLoS One 6:e27877, 2011

5. Burgess A, Huang Y, Querbes W, Sah DW, Hynynen K: Focused ultrasound for targeted delivery of siRNA and efficient knockdown of Htt expression. J Control Release 163:125129,2012

6. Christian E, Yu C, Apuzzo ML: Focused ultrasound: relevant history and prospects for the addition of mechanical energy to the neurosurgical armamentarium. World Neurosurg 82:354-365, 2014

7. Chung AH, Jolesz FA, Hynynen K: Thermal dosimetry of a focused ultrasound beam in vivo by magnetic resonance imaging. Med Phys 26:2017-2026, 1999

8. Clement GT, Hynynen K: A non-invasive method for focusing ultrasound through the human skull. Phys Med Biol 47:1219-1236, 2002

9. Cline HE, Hynynen K, Hardy CJ, Watkins RD, Schenck JF, Jolesz FA: MR temperature mapping of focused ultrasound surgery. Magn Reson Med 31:628-636, 1994

10. Cline HE, Hynynen K, Watkins RD, Adams WJ, Schenck JF, Ettinger RH, et al: Focused US system for MR imagingguided tumor ablation. Radiology 194:731-737, 1995

11. Cline HE, Schenck JF, Watkins RD, Hynynen K, Jolesz FA: Magnetic resonance-guided thermal surgery. Magn Reson Med 30:98-106, 1993

12. Curie PJ, Curie P: [Crystal physics: Development by pressure of polar electricity in hemihedral crystals with inclined faces.] C R Hebd Seances Acad Sci 91:291, 1880 (Fr)

13. Damianou $\mathrm{C}$, Hynynen $\mathrm{K}$ : The effect of various physical 
parameters on the size and shape of necrosed tissue volume during ultrasound surgery. J Acoust Soc Am 95:1641-1649, 1994

14. Elias WJ, Huss D, Voss T, Loomba J, Khaled M, Zadicario E, et al: A pilot study of focused ultrasound thalamotomy for essential tremor. N Engl J Med 369:640-648, 2013

15. Elias WJ, Lipsman N, Ondo WG, Ghanouni P, Kim YG, Lee $\mathrm{W}$, et al: A randomized trial of focused ultrasound thalamotomy for essential tremor. N Engl J Med 375:730-739, 2016

16. Frenkel V, Oberoi J, Stone MJ, Park M, Deng C, Wood BJ, et al: Pulsed high-intensity focused ultrasound enhances thrombolysis in an in vitro model. Radiology 239:86-93, 2006

17. Fry FJ, Ades HW, Fry WJ: Production of reversible changes in the central nervous system by ultrasound. Science 127:8384, 1958

18. Fry WJ, Fry FJ: Fundamental neurological research and human neurosurgery using intense ultrasound. IRE Trans Med Electron ME-7:166-181, 1960

19. Fry WJ, Mosberg WH Jr, Barnard JW, Fry FJ: Production of focal destructive lesions in the central nervous system with ultrasound. J Neurosurg 11:471-478, 1954

20. Gruetzmacher J: Piezoelektrischer Kristall mit Ultraschallkonvergenz. Z Phys 96:342-349, 1935

21. Guthkelch AN, Carter LP, Cassady JR, Hynynen KH, Iacono RP, Johnson PC, et al: Treatment of malignant brain tumors with focused ultrasound hyperthermia and radiation: results of a phase I trial. J Neurooncol 10:271-284, 1991

22. Hayashi S: Einflüsse der Ultraschallwellen auf das Wachstum des Rattensarkams. J Med Sci Biophysics, Japan 162, 1938

23. Heimburger RF, Fry FJ, Franklin TD, Eggleton RC: Ultrasound potentiation of chemotherapy for brain malignancy, in White D (ed): Ultrasound in Medicine. New York: Plenum Press, 1975, pp 273-281

24. Horvath J: Morphologische Untersuchungen über die Wirkung der Ultraschallwellen auf das Karzinomgewebe. Strahlentherapie 77:279, 1948

25. Hsiao YH, Kuo SJ, Tsai HD, Chou MC, Yeh GP: Clinical application of high-intensity focused ultrasound in cancer therapy. J Cancer 7:225-231, 2016

26. Huang Y, Alkins R, Schwartz ML, Hynynen K: Opening the blood-brain barrier with MR imaging-guided focused ultrasound: preclinical testing on a trans-human skull porcine model. Radiology 282:123-130, 2017

27. Hynynen K, Clement GT, McDannold N, Vykhodtseva N, King R, White PJ, et al: 500-element ultrasound phased array system for noninvasive focal surgery of the brain: a preliminary rabbit study with ex vivo human skulls. Magn Reson Med 52:100-107, 2004

28. Hynynen K, Freund WR, Cline HE, Chung AH, Watkins $\mathrm{RD}$, Vetro JP, et al: A clinical, noninvasive, MR imagingmonitored ultrasound surgery method. Radiographics 16:185-195, 1996

29. Hynynen K, Jolesz FA: Demonstration of potential noninvasive ultrasound brain therapy through an intact skull. Ultrasound Med Biol 24:275-283, 1998

30. Hynynen K, McDannold N, Sheikov NA, Jolesz FA, Vykhodtseva N: Local and reversible blood-brain barrier disruption by noninvasive focused ultrasound at frequencies suitable for trans-skull sonications. Neuroimage 24:12-20, 2005

31. Hynynen K, McDannold N, Vykhodtseva N, Jolesz FA: Noninvasive MR imaging-guided focal opening of the bloodbrain barrier in rabbits. Radiology 220:640-646, 2001

32. Hynynen K, Vykhodtseva NI, Chung AH, Sorrentino V, Colucci V, Jolesz FA: Thermal effects of focused ultrasound on the brain: determination with MR imaging. Radiology 204:247-253, 1997

33. Jagannathan J, Sanghvi NT, Crum LA, Yen CP, Medel R, Dumont AS, et al: High-intensity focused ultrasound surgery of the brain: part $1-$ a historical perspective with modern applications. Neurosurgery 64:201-211, 2009

34. Jeanmonod D, Werner B, Morel A, Michels L, Zadicario E, Schiff G, et al: Transcranial magnetic resonance imagingguided focused ultrasound: noninvasive central lateral thalamotomy for chronic neuropathic pain. Neurosurg Focus 32(1):E1, 2012

35. Jolesz FA: MRI-guided focused ultrasound surgery. Annu Rev Med 60:417-430, 2009

36. Jordão JF, Ayala-Grosso CA, Markham K, Huang Y, Chopra R, McLaurin J, et al: Antibodies targeted to the brain with image-guided focused ultrasound reduces amyloid-beta plaque load in the TgCRND8 mouse model of Alzheimer's disease. PLoS One 5:e10549, 2010

37. Jung HH, Kim SJ, Roh D, Chang JG, Chang WS, Kweon EJ, et al: Bilateral thermal capsulotomy with MR-guided focused ultrasound for patients with treatment-refractory obsessivecompulsive disorder: a proof-of-concept study. Mol Psychiatry 20:1205-1211, 2015

38. Kinoshita M, McDannold N, Jolesz FA, Hynynen K: Noninvasive localized delivery of Herceptin to the mouse brain by MRI-guided focused ultrasound-induced blood-brain barrier disruption. Proc Natl Acad Sci U S A 103:11719-11723, 2006

39. Lindstrom PA: Prefrontal ultrasonic irradiation - a substitute for lobotomy. AMA Arch Neurol Psychiatry 72:399-425, 1954

40. Lipsman N, Schwartz ML, Huang Y, Lee L, Sankar T, Chapman M, et al: MR-guided focused ultrasound thalamotomy for essential tremor: a proof-of-concept study. Lancet Neurol 12:462-468, 2013

41. Liu HL, Hua MY, Chen PY, Chu PC, Pan CH, Yang HW, et al: Blood-brain barrier disruption with focused ultrasound enhances delivery of chemotherapeutic drugs for glioblastoma treatment. Radiology 255:415-425, 2010

42. Lynn JG, Putnam TJ: Histology of cerebral lesions produced by focused ultrasound. Am J Pathol 20:637-649, 1944

43. Lynn JG, Zwemer RL, Chick AJ, Miller AE: A new method for the generation and use of focused ultrasound in experimental biology. J Gen Physiol 26:179-193, 1942

44. Magara A, Bühler R, Moser D, Kowalski M, Pourtehrani P, Jeanmonod D: First experience with MR-guided focused ultrasound in the treatment of Parkinson's disease. J Ther Ultrasound 2:11, 2014

45. McDannold N, Arvanitis CD, Vykhodtseva N, Livingstone MS: Temporary disruption of the blood-brain barrier by use of ultrasound and microbubbles: safety and efficacy evaluation in rhesus macaques. Cancer Res 72:3652-3663, 2012

46. McDannold N, Clement GT, Black P, Jolesz F, Hynynen K: Transcranial magnetic resonance imaging- guided focused ultrasound surgery of brain tumors: initial findings in 3 patients. Neurosurgery 66:323-332, 2010

47. McDannold N, Hynynen K, Jolesz F: MRI monitoring of the thermal ablation of tissue: effects of long exposure times. J Magn Reson Imaging 13:421-427, 2001

48. McDannold N, Vykhodtseva N, Jolesz FA, Hynynen K: MRI investigation of the threshold for thermally induced bloodbrain barrier disruption and brain tissue damage in the rabbit brain. Magn Reson Med 51:913-923, 2004

49. Meshorer A, Prionas SD, Fajardo LF, Meyer JL, Hahn GM, Martinez AA: The effects of hyperthermia on normal mesenchymal tissues. Application of a histologic grading system. Arch Pathol Lab Med 107:328-334, 1983

50. Mesiwala AH, Farrell L, Wenzel HJ, Silbergeld DL, Crum LA, Winn HR, et al: High-intensity focused ultrasound selectively disrupts the blood-brain barrier in vivo. Ultrasound Med Biol 28:389-400, 2002

51. Meyers R, Fry WJ, Fry FJ, Dreyer LL, Schultz DF, Noyes RF: Early experiences with ultrasonic irradiation of the pallidofu- 
gal and nigral complexes in hyperkinetic and hypertonic disorders. J Neurosurg 16:32-54, 1959

52. Min BK, Bystritsky A, Jung KI, Fischer K, Zhang Y, Maeng LS, et al: Focused ultrasound-mediated suppression of chemically-induced acute epileptic EEG activity. BMC Neurosci 12:23, 2011

53. Mislow JM, Golby AJ, Black PM: Origins of intraoperative MRI. Neurosurg Clin N Am 20:137-146, 2009

54. Monteith SJ, Kassell NF, Goren O, Harnof S: Transcranial MR-guided focused ultrasound sonothrombolysis in the treatment of intracerebral hemorrhage. Neurosurg Focus 34(5):E14, 2013

55. Monteith SJ, Medel R, Kassell NF, Wintermark M, Eames M, Snell J, et al: Transcranial magnetic resonance-guided focused ultrasound surgery for trigeminal neuralgia: a cadaveric and laboratory feasibility study. J Neurosurg 118:319328, 2013

56. Pohlman R: Die Ultraschalltherapie, Praktische Anwendung des Ultraschalls in der Medizin. Bern: Hans Huber, 1951

57. Ram Z, Cohen ZR, Harnof S, Tal S, Faibel M, Nass D, et al: Magnetic resonance imaging-guided, high-intensity focused ultrasound for brain tumor therapy. Neurosurgery 59:949956, 2006

58. Schlesinger I, Eran A, Sinai A, Erikh I, Nassar M, Goldsher D, et al: MRI guided focused ultrasound thalamotomy for moderate-to-severe tremor in Parkinson's disease. Parkinsons Dis 2015:219149, 2015

59. Seip R, Vanbaren P, Ebbini ES: Dynamic focusing in ultrasound hyperthermia treatments using implantable hydrophone arrays. IEEE Trans Ultrason Ferroelectr Freq Control 41:706-713, 1994

60. Sheikov N, McDannold N, Vykhodtseva N, Jolesz F, Hynynen $\mathrm{K}$ : Cellular mechanisms of the blood-brain barrier opening induced by ultrasound in presence of microbubbles. Ultrasound Med Biol 30:979-989, 2004

61. Stone MJ, Frenkel V, Dromi S, Thomas P, Lewis RP, Li KC, et al: Pulsed-high intensity focused ultrasound enhanced tPA mediated thrombolysis in a novel in vivo clot model, a pilot study. Thromb Res 121:193-202, 2007

62. Tempany CM, McDannold NJ, Hynynen K, Jolesz FA: Focused ultrasound surgery in oncology: overview and principles. Radiology 259:39-56, 2011

63. Treat LH, McDannold N, Vykhodtseva N, Zhang Y, Tam K, Hynynen K: Targeted delivery of doxorubicin to the rat brain at therapeutic levels using MRI-guided focused ultrasound. Int J Cancer 121:901-907, 2007

64. Treat LH, McDannold N, Zhang Y, Vykhodtseva N, Hynynen $\mathrm{K}$ : Improved anti-tumor effect of liposomal doxorubicin after targeted blood-brain barrier disruption by MRI-guided focused ultrasound in rat glioma. Ultrasound Med Biol 38:1716-1725, 2012

65. Tsivgoulis G, Eggers J, Ribo M, Perren F, Saqqur M, Rubiera M, et al: Safety and efficacy of ultrasound-enhanced thrombolysis: a comprehensive review and meta-analysis of randomized and nonrandomized studies. Stroke 41:280-287, 2010

66. Vykhodtseva N, Sorrentino V, Jolesz FA, Bronson RT, Hynynen K: MRI detection of the thermal effects of focused ultrasound on the brain. Ultrasound Med Biol 26:871-880, 2000

67. Vykhodtseva NI, Hynynen K, Damianou C: Histologic effects of high intensity pulsed ultrasound exposure with subharmonic emission in rabbit brain in vivo. Ultrasound Med Biol 21:969-979, 1995

68. Zaaroor M, Sinai A, Goldsher D, Eran A, Nassar M, Schlesinger I: Magnetic resonance-guided focused ultrasound thalamotomy for tremor: a report of 30 Parkinson's disease and essential tremor cases. J Neurosurg [epub ahead of print February 24, 2017; DOI: 10.3171/2016.10.JNS16758]

\section{Disclosures}

Dr. Cosgrove: clinical or research support for this study from InSightec Inc.

\section{Author Contributions}

Conception and design: Cosgrove, Harary, Segar. Drafting the article: Harary, Segar, Huang, Tafel, Valdes. Critically revising the article: Cosgrove, Harary, Segar. Reviewed submitted version of manuscript: Cosgrove, Harary, Segar. Approved the final version of the manuscript on behalf of all authors: Cosgrove. Administrative/technical/material support: Harary. Study supervision: Cosgrove.

\section{Correspondence}

G. Rees Cosgrove: Brigham and Women's Hospital, Boston, MA. rcosgrove2@partners.org. 